\title{
Analysis of the Efficiency of the Recloser Function of LV Smart Switchboards
}

\section{Judith Pálfi, Miklós Tompa, Péter Holcsik}

Óbuda University, Kandó Kálmán Faculty of Electrical Engineering, Power

System Department, Research Group of Applied Disciplines and Technologies in Energetics, Bécsi út 96, H-1034 Budapest, Hungary

palfi.judith@kvk.uni-obuda.hu, tompa.miklos@kksz-projekt.hu, peter.holcsik@elmu.hu

\begin{abstract}
The improvement of the quality of services is the main target of the electricity suppliers. This can be achieved by minimizing the number and duration in time of the power outages. The reliability indicators show the quality of the system. The quality of the services can be increased by proper maintenance, proper renovation activities and the implementation of advanced tools and functions into the system. Smart switchboard (SSB) devices are provided with modern and innovative functions which support the activity of the low voltage $(\mathrm{LV})$ distribution network operators. Remote control and monitoring, fault location identification support, supply of on-line load-flow input data, and automatic recloser are only some examples of the newly available technologies. In this paper the improvement of the $L V$ reliability indicators by using the recloser function of the $S B B$ 's is presented.
\end{abstract}

Keywords: LV network; quality of service; smart switchboard; recloser; fault location

\section{Introduction}

The AD\&TE research group recommends the introduction of advanced switchboards to the power supply companies. This equipment is the smart switchboard (SSB). By the introduction of the SSB's, the duration of the power outages can be significantly reduced. This can be achieved by using the reclose function of the SSB (more detailed information about the reclose function of the SSB is provided in Section 1.1). Currently available LV swichboards are not equipped with the reclose function [1] which has been developed by the authors of this paper.

In this paper the research team will formulate recommendations to the electricity companies about the location of these devices. This recommendation is presented in the form of a function, the so-called efficiency function, which shows the expected improvement of the quality of services [2] [3]. 


\subsection{Distribution Network Switchboards Today and Tomorow}

The fuse protecting a section of the LV network melts down when a short circuit current occurs. The fuse protects the network from the damages caused by the short circuit currents. (The eventual faults of the measuring stations are not considered in this paper.)

The fuses are located in the outdoor or indoor switchboards (see Figure 1).
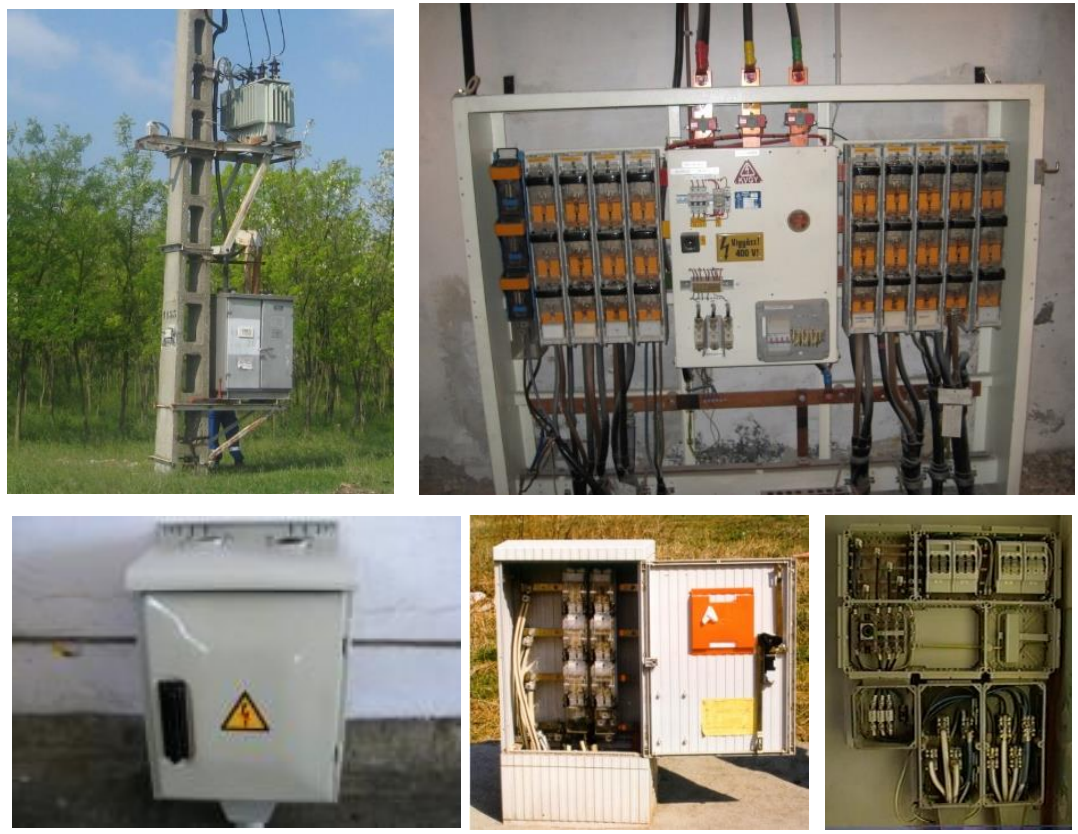

Figure 1

Outdoor and indoor switchboards in current use

Within the LV distribution network the switchboards can be found in different positions [4]. The LV network begins from the distribution equipment on the 0,4 $\mathrm{kV}$ side of the medium voltage (MV) / LV transformer stations (see upper part of Fig. 1) and ends by the consumers. A large number of switchboards can operate within a network depending on the protection design (see bottom part of Figure 1). In Figure 2 a typical LV network topology is shown and possible locations for the switchboards are represented.

Nowadays, if a fuse melts down, the supervisory dispatcher can detect it only from the error related calls [5]. On-line remote alarm- or remote monitoring systems are not available. Due to the technology of the fuse, the remote reclose is not possible. 


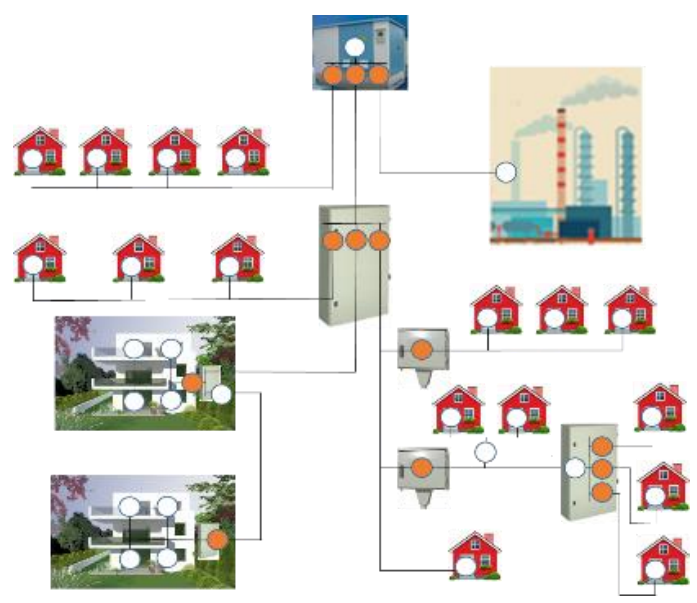

Figure 2

Typical LV network topology. The swichboards are highlighted with orange dots.

The remote alarm and monitoring functions are a basic condition for the on-line determination of the fault location (for details, please see earlier [6] paper of the research group on this subject). In the near future remote operation will play a significant role in handling the temporary short circuits.

\subsection{Temporary Short Circuits}

The temporary short circuits are caused by external influences (e.g. tree branch reaching to the overhead lines, arc-over caused by heavy rains, phase swinging due to powerful wind blasts, etc.) or short period overloads in the network. The common characteristic of these faults is that their repair requires only the change of the fuse(s) (1, 2 or 3 fuses, depending on how many phases were involved in the incident). No other intervention or installation works are required. The electricians will not have to be sent out to the location of the temporary short circuits as soon as the swicthboards will be provided with remote control systems [7].

\subsection{Smart Switchboards}

In order to implement the remote operation, the fuses will have to be replaced with circuit breakers. Contrary to the fuses, the circuit breakers do not have to be replaced following a short circuit power breakdown. Depending on their producer and type, the circuit breakers are capable of numerous operations during their working life. Measuring equipment and analysis systems [8] for the measured values (hardware and software) are to be integrated into the SSB's in order to detect the short circuits and to be able to issue the OFF instructions to the circuit breakers. 
The SSB concept stands for a remote controlled LV switchboard which uses a circuit breaker for the dismantling of the short circuit current. The detection of the short circuit current is done by using a detection equipment together with the corresponding measurement analysis system. It is suitable for remote switch-on (circuit breaker activation) which, if necessary, can be turned to clogging mode. It contains the possibility of visible interruption point and earthing as well.

The visible interruption point and the earthing functions are required for ensuring the life, health and safety protection during the maintenance, reconstruction, etc. works.

The remote monitoring functions could actively or passively monitor the current, the voltage and the performance of the LV system.

The implementation of an automatic recloser, a so-called reclose function into the SSB is also possible.

\subsection{The Reclose Function}

When the reclose function is activated, the circuit breaker recloses after a previously specified time period following the defense action. If the defense continues to detect the short circuit, the circuit breaker opens again. Following this and after another pre-set time period, the automatics will close the contacts of the circuit breaker again. The automatics seeks to switch back two times (two cycles). The final release is activated if the short circuit persists. Nowadays, the reclose technology is already in use for MV networks [9]. Its working principle and the pre-set time periods for MV networks are shown in Figure 3.

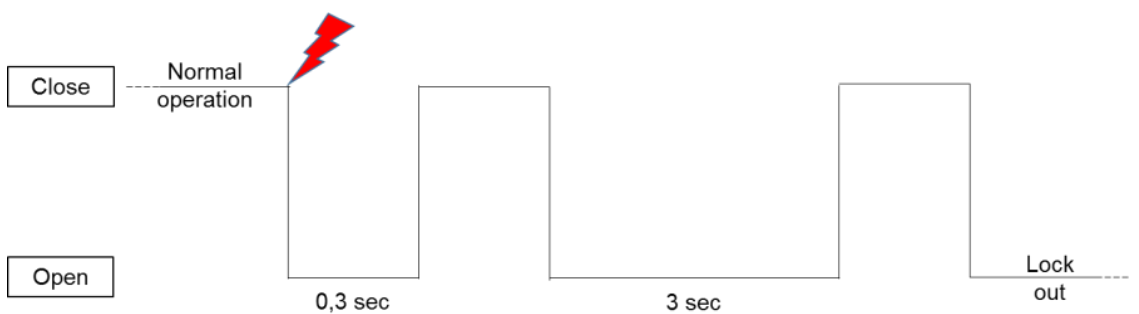

Figure 3

Working principle and pre-set time periods of the reclose function in case of MV networks

The implementation of the reclose function into the LV network will optimize the work of the electricians (they do not have to spend any more time going out to detect the faults in the network) and minimize the length of the LV power outages caused by short circuits. The earlier time consuming process (see Figure 4) is reduced to a few minutes (see Figure 3). 


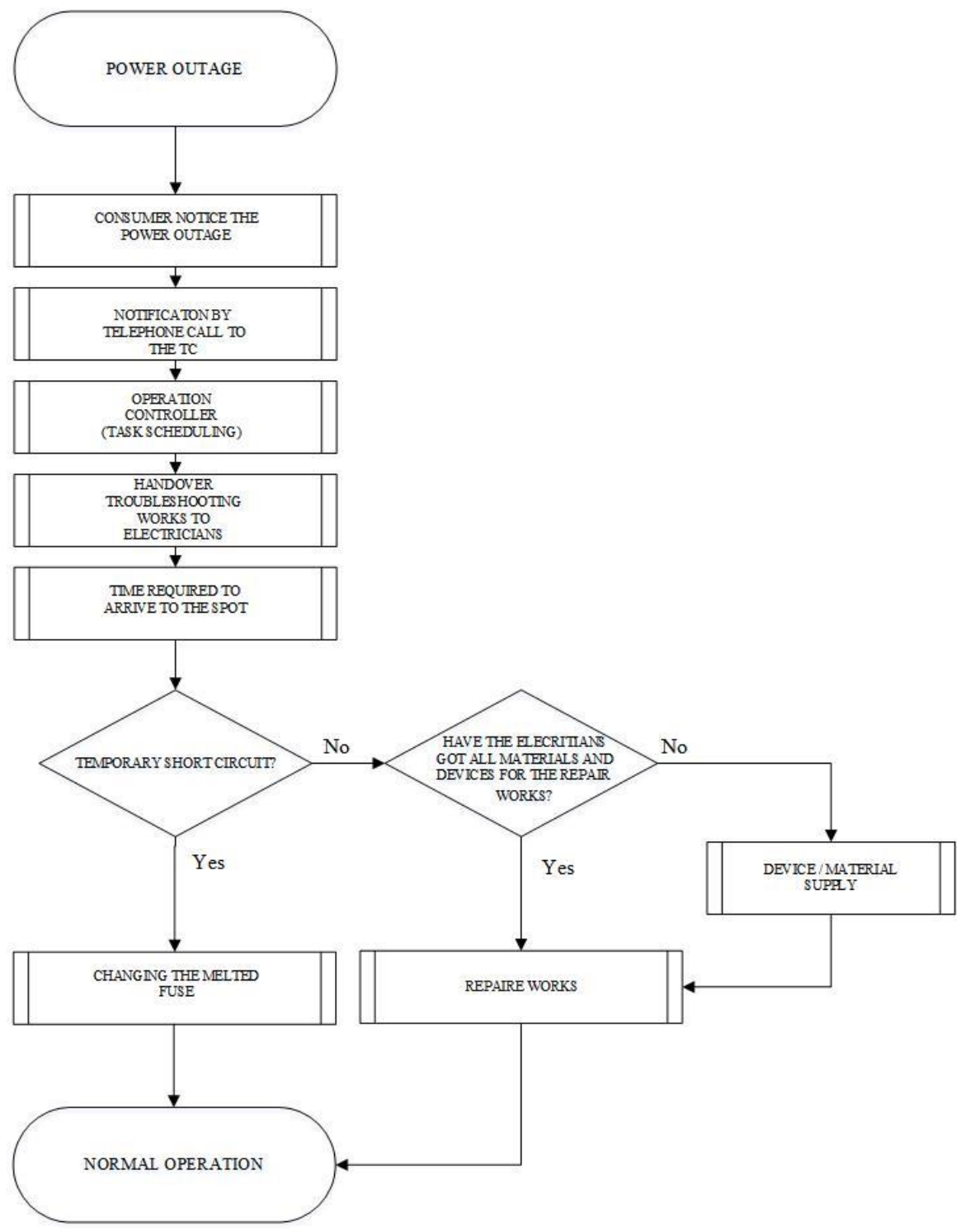

Figure 4

The LV power outage protection flow chart

The AD\&TE research team has analized the improvement of the quality of the LV networks following the implementation of the SSB's and the efficiency of these advanced tools. The efficiency can be measured by the network's indicators of quality (for network quality indicators please see Section 2.1). 


\section{Method Used for Analysing the Efficiency of SSB's}

When switchboards serving a large number of customers are upgraded to SSB's the related efficiency of these tools increases, that is a small number of devices protect a large number of customers [10]. This means that the efficiency of the reclose function implementation will be higher for those swichboards of which melting down can impact a larger number of customers. The efficiency will decrease as the number of customerss served by the upgraded switchboards is smaller.

The research group recommends to the power supplier companies to begin the implementation of the SSB's with the switchboards connected to larger number of customers.

By carrying out the study of the efficiency the research group determined the number of customers for which it is worthwhile upgrading the existing equipment. A cumulative efficiency function has been developed. This function shows the SAIDI improvement (Section 2.1) which could be achieved when changing some of the fuses to SSB's.

The research group examined the data collected from the LV power outages during years 2014 and 2015. The improvement of the SAIDI indicator has been determined assuming that during these 2 years SSB's with reclose function would have been used instead of the existing equipment (SAIDI indicator in section 2.1).

The input data for the study was provided by ELMÜ Network ltd and ÉMÁSZ Network ltd.

\subsection{The Impact of LV Power Outages on SAIDI and SAIFI Indicators}

The electricity suppliers use several indicators for measuring the quality of electricity networks. The Hungarian Energy and Public Utility Regulatory Authority is following two indicators and expects their improvement by the Hungarian electricity suppliers. These two indicators are the System Average Interruption Duration Index (SAIDI) and the System Average Interruption Frequency Index (SAIFI). [2] [11]

Nowadays, a LV power outage duration is taken into account from the time of the notification of the error until the time of reconnection of the customers. This time period is the outage time $(U i)$.

Another factor influencing the SAIDI is the number of customers affected by the power outage $(\mathrm{Ni})$. 
The electricity suppliers keep record of how many customers are affected by the breakdown of a certain equipment. Consequently, the impact on customers by the LV outage $i$ can be determined from the IT databases.

The total number of customers $\left(N_{T}\right)$ during a particular year for a particular company, e.g. ELMÜ or ÉMÁSZ is a constant value (pieces).

"The SAIDI network quality indicator is given by [2]:

$S A I D I=\frac{\sum_{x=1}^{n}\left(U_{i} \cdot N_{i}\right)}{N_{T}}[\mathrm{sec}]$

where $N_{i}$ is the number of customers and $U_{i}$ is the annual outage time for location $i$, and $N_{T}$ is the total number of customers served.

In other words [2],

$S A I D I=\frac{\text { sum of all customer interruption durations }}{\text { total number of customers served }}$

SAIFI stands for the average number of power outages in a year related to the total number of customers.

The SAIFI network quality indicator is given by [2]:

SAIFI $=\frac{\sum_{x=1}^{n}\left(\lambda_{i} \cdot N_{i}\right)}{N_{T}}[\mathrm{sec}]$

where $\lambda_{i}$ is the failure rate, $N_{i}$ is the number of customers for location $i$ and $N_{T}$ is the total number of customers served. In other words,

SAIFI $=\frac{\text { total number of customer interruptions }}{\text { total number of customers served }}$

".[2]

The SSB device is installed on LV networks. Table 1 shows the ratio of MV and LV outages in the SAIFI and SAIDI indicators.

Table I

MV/LV ratio in SAIFIs and SAIDIs datas of ELMÜ Hálózati ltd., head of Pest,

01. -08.2015

\begin{tabular}{|c|c|c|}
\hline & SAIFI & SAIDI \\
\hline LV & 0.09 & 0.72 \\
\hline MV & 0.53 & 0.85 \\
\hline Sum of LV and MV & 0.62 & 1.57 \\
\hline Ratio of the LV / MV & $14.51 \% / 85.49 \%$ & $45.85 \% / 54.14 \%$ \\
\hline
\end{tabular}


From the data in Table 1, it can be seen that the power outages in the LV networks have a significantly smaller influence on the SAIFI indicators $(14.51 \%)$ than on the SAIDI indicators $(45.85 \%)$. Therefore, the AD\&TE research group considered the calculation method of SAIDI for setting up the cumulative efficiency function. The results are given in minutes, similarly to the SAIDI indicator.

The power outage data (outage time, number of affected customers) are gathered by the electricity suppliers based on the worksheets filled out by the electricians. These worksheets are checked and validated by the LV operation controllers [12] [13] [14].

\subsection{The Analysis of the Worksheets}

The electricity suppliers are recording into their own IT system the customers' calls related to the power outages [15] [16]. These notices are then converted into digital worksheets by the LV operators. The worksheets are distributed to the electricians taking into account their current geographical location, their skills and other relevant information. Figure 5 illustrates the input interface of a worksheet.

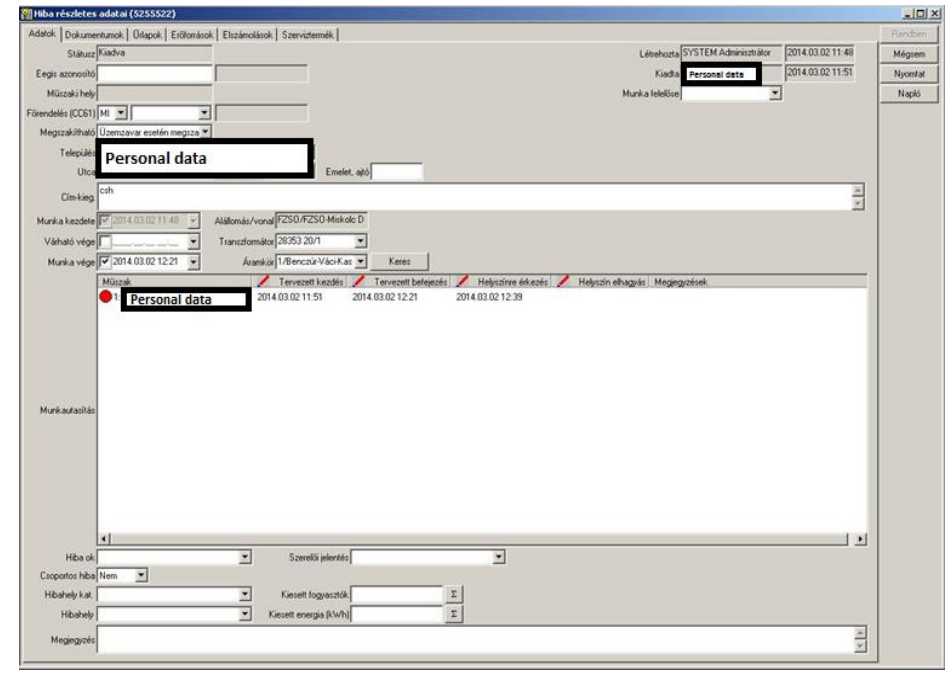

Figure 5

Electrician worksheet from ELMÜ-ÉMÁSZ‘s work management and LV operation control system

After the repair work has been completed, the electrician fills out the worksheet. This is done with the help of drop-down optional lists. He will choose and complete the lists with information related to the cause of the error, whether one or more customers were affected, the type and category of the failed equipment (e.g. transformer station, switchboard, devices of the measuring station, etc.) and/or device (cable, overhead line, fuse, etc.). 
In addition to the drop-down lists, free texts can be introduced as well. These could be notes and/or explanations related to the size of the replaced lining measured in amper or the type of the repair which has been carried out (e.g. replacement of a circuit breaker, measuring equipment exchange, reconnection of a cable, etc.).

The information concerning the type of short circuits which caused the power outage (temporary or long term) is not recorded in the worksheets. Whether only a fuse was changed or a more complex repair work was carried out (e.g. cutting the branches of trees, reconnection of collapsed overhead lines, etc.) is not specified. Due to this reason, the database in its current form does not allow for a clear and rapid detection of the power outages caused by short circuits. Concerning that, the worksheets must be analyzed one by one, taking into account all the information which has been given in the free text notes and in the drop-down lists as well.

It can happen that the electrician replaced a fuse and the reason of the melt down of it was not a temporary short circuit but for example, a cable of the network was cut by a branch of a tree or by an excavator working nearby.

During the two years period of the study a total number of 21351 worksheets were generated (after data cleaning and not including the faults of the public lighting and of the measuring stations). The examination of the worksheets, one by one, would have taken more than 550 working hours. Therefore, the research group decided to apply a sampling method for the analysis of this large amount of information. [17]

\subsection{Selection of the Sample}

The analyzed population are the worksheets generated by ELMÜ ÉMÁSZ during the years 2014 and 2015. The sampling frame consists of as many as 21351 worksheets. Through the sampling process the randomly selected information from the data gathered in 3-3 weeks of the 2 years period was processed.

The selected weeks are shown in Table 2.

Table 2

Weeks randomly selected in years 2014 and 2015

\begin{tabular}{|l|c|c|}
\hline & 2014 & 2015 \\
\hline \multirow{3}{*}{$\begin{array}{l}\text { The calendar number } \\
\text { of the selected weeks }\end{array}$} & 09 & 05 \\
\cline { 2 - 3 } & 13 & 15 \\
\cline { 2 - 3 } & 37 & 28 \\
\hline
\end{tabular}

The free text entries of the selected weeks' worksheets were filtered from the point of view of whether the reason of the error was clearly due to a temporary short circuit or not. Manual analysis was not carried out in the cases in which the power outage was not due to temporary short circuits. Further possibilities for filtering the free text entries are described in Section 7. After filtering the 3-3 weeks' worksheets 2060 pieces remained for manual analysis. 


\section{Analysis of the Sample and Results}

The sample selected and filtered as described in Section 2.3 consists of 2060 worksheets. The data were analyzed manually, one by one. In the analysis of the worksheets (see Section 2.2) the information related to the duration of the intervention of the electricians and the description of the type of the faults was considered. The faults were categorized in faults which could have been saved by providing the SSB's and faults where the provision of the SSB's would have had no positive impact. A similar selection has been carried out from the point of view of the customers.

The results of the analysis are presented in Table 3.

Table 3

Results of the analyzed sample

\begin{tabular}{c|c|c|c}
$\begin{array}{c}\text { Calendar } \\
\text { number of } \\
\text { selected } \\
\text { weeks }\end{array}$ & $\begin{array}{c}\text { Number of } \\
\text { events which } \\
\text { could have been } \\
\text { saved by } \\
\text { providing SSB 's } \\
\text { (pieces) }\end{array}$ & $\begin{array}{c}\text { Number of } \\
\text { customers who } \\
\text { could have been } \\
\text { saved by providing } \\
\text { SSB's (pieces) }\end{array}$ & $\begin{array}{c}\text { Outage time which } \\
\text { could have been } \\
\text { saved by providing } \\
\text { SSB's (minutes) }\end{array}$ \\
\hline 2014. 09 & 123 & 5771 & 19.448 \\
2014. $13^{\text {th }}$ & 88 & 3289 & 12.548 \\
2014. $37^{\text {th }}$ & 87 & 3548 & 14.241 \\
2015. $05^{\text {th }}$ & 158 & 6092 & 23.566 \\
2015. $15^{\text {th }}$ & 94 & 3609 & 10.646 \\
2015. $28^{\text {th }}$ & 1026 & 32362 & 354.155 \\
\hline Total: & $\mathbf{1 5 7 6}$ & $\mathbf{5 4 6 7 1}$ & $\mathbf{4 3 4 6 0 4}$
\end{tabular}

Based on the results shown in Table 3 temporary outage was recorded in 1576 cases in which the electricians had to only replace the melted fuse(s). Consequently, 1576 power outages (which affected 5467 customers during a total of 434.604 minutes) could have been minimized by implementing the SSB's. Extrapolating the results the annual theoretical maximum efficiency can be obtained.

\subsection{Determination of the Annual Maximum Efficiency}

The theoretical maximum of SAIDI improvement can be calculated from the data of Table 3.

In $1^{\text {st }}$ result column of Table 4 the LV power outages are shown which affected more than one customer within the given week. This data shows the load of power outages in that week. 
Table 4

Determination of the maximum efficiency

\begin{tabular}{|c|c|c|c|c|c|c|c|c|}
\hline 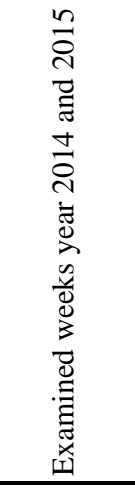 & 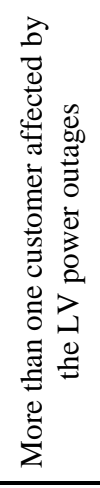 & 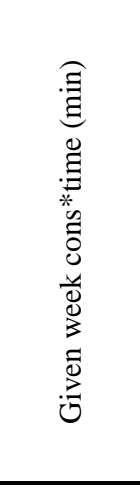 & 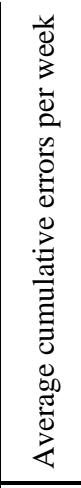 & 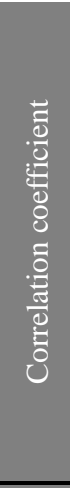 & 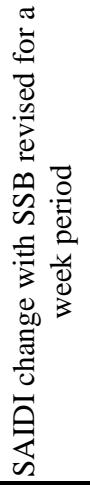 & 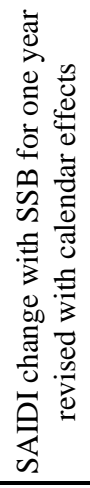 & 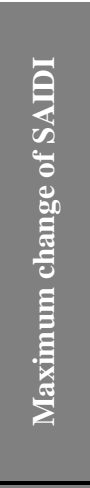 & 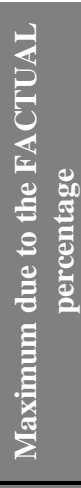 \\
\hline $201409^{\text {th }}$ & 1107 & 902801 & 6171 & 5.57 & 2.23 & 38.83 & & \\
\hline $201413^{\text {th }}$ & 2730 & 425350 & 6171 & 2.26 & 0.43 & 7.42 & 50.73 & $25 \%$ \\
\hline $201437^{\text {th }}$ & 5920 & 556267 & 6171 & 1.04 & 0.26 & 4.47 & & \\
\hline $201505^{\text {th }}$ & 790 & 995045 & 4778 & 6.05 & 2.67 & 46.44 & & \\
\hline $201515^{\text {th }}$ & 1410 & 381228 & 4778 & 3.39 & 0.57 & 9.97 & 67.72 & $29 \%$ \\
\hline $201528^{\text {th }}$ & 36820 & 11298735 & 4778 & 0.13 & 0.65 & 11.31 & & \\
\hline
\end{tabular}

It can be seen that while during the $5^{\text {th }}$ week of 2015 there were only 790 power outages in the $28^{\text {th }}$ week there were 36.820 . The later figure was generated by the extreme weather conditions.

The $2^{\text {nd }}$ result column of Table 4 shows the value of the numerator of SAIDI indicator formula.

In order to extrapolate the measured data it is necessary to examine the way the number of power outages from the considered week relate to the annual week average. This relation is shown in the correlation coefficient column of Table 4 .

ELMÜ ÉMÁSZ calculated the quality indicators in 2014 with 2.252 .508 pcs customers, in 2015 with 2.246 .941 pcs customers. By using these two values and the correction factor the values given in $4^{\text {th }}$ column of Table 4 were determined. The extrapolation was done by carrying out the correction and following the calculation method of the SAIDI indicator.

From the weekly results it can be determined that if SSB's would have been installed in all the possible locations of the LV network, the SAIDI indicator would have been lower with 50.73 minutes in 2014. The 205.2 minutes represents $25 \%$ of ÉMÁSZ ELMÜ factual data. In 2015 this value is 67.72 minutes which stands for $29 \%$ of the annual factual data of 231.32 minutes. 


\subsection{Distributions and the Comparison of Distributions}

The research group's preliminary assumption was that the distribution of the measured data and the number of customers behind the fuse boxes from the network correlate with each other. In order to verify this hypothesis, the number of customers affected by the power outages was examined.
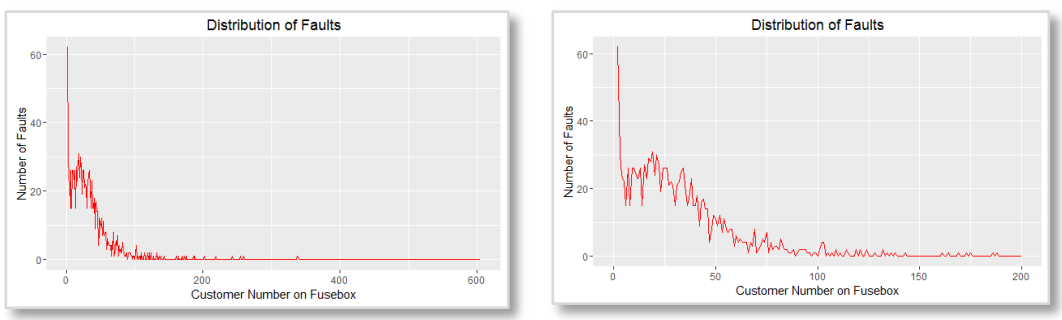

Figure 6

Distributions of the costumers behind the faults, data measured in 2014 and 2015

Left side: normal plot, right side: the plot is zoomed along the horizontal axis

between 0 and 200 costumers

The distribution illustrated on Figure 6 has been compared with the distribution of the number of customers from behind all of the fuse boxes of the ELMÜ ÉMÁSZ LV network.

The distributions of the customers numbers behind the fuse boxes is shown ib Figure 7.
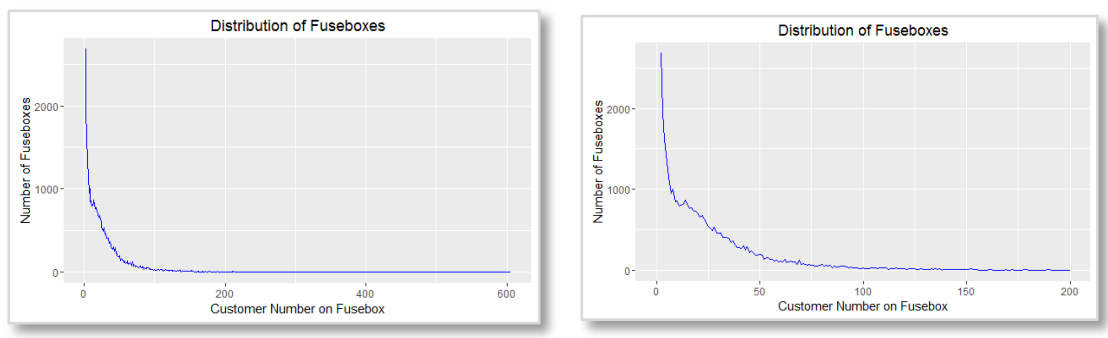

Figure 7

Distributions of the customers behind the fuse boxes on the ELMÜ-ÉMÁSZ network, 2016

Left side: normal plot, right side: the plot is zoomed along the horizontal axis between 0 and 200 customers

Data of Figure 6 and Figure 7 illustrated in one coordinate system: 


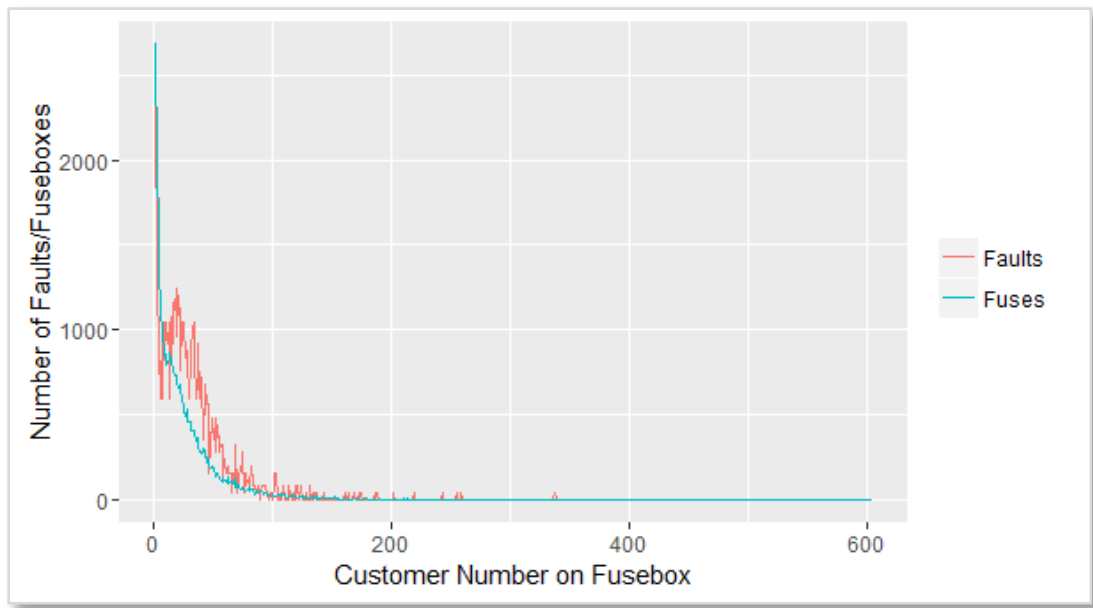

Figure 8

Distribution of the costumers numbers behind the measured fuse boxes and number of faults in 2014 and 2015

Figure 8 shows that the assumption of the research group was confirmed: both curves show an exponential decreasing along the horizontal axis. However, beside the correlation, differences can be observed between the two curves. The reason for these differences is detailed in Section 6.

\section{The Efficiency Function}

The recommendation described in Section 2 was to begin the implementation of the SSB's into the equipments connected to larger number of customers.

By carrying out the study of the efficiency, the research group determined the number of customers for which it is worth upgrading the existing equipment. A cumulative efficiency function has been developed. This function shows the SAIDI improvement (Section 2.1) which could be achieved when changing some of the fuses to SSB's.

For example, in case $N=105$ customers:

Cumulative utility $=\sum_{N=105}^{N_{\max }}\left(N_{i} \cdot U_{i}\right)$

where $N$ is the number of customers in the LV network behind the fuse, $N_{\max }$ is the maximum number of customers behind a fuse, $N_{\mathrm{i}}$ is the number of customers affected by the power outage $i, U_{\mathrm{i}}$ is the duration of the power outage $i$. 
The cumulative efficiency function for the measured weeks is given in Figure 9.

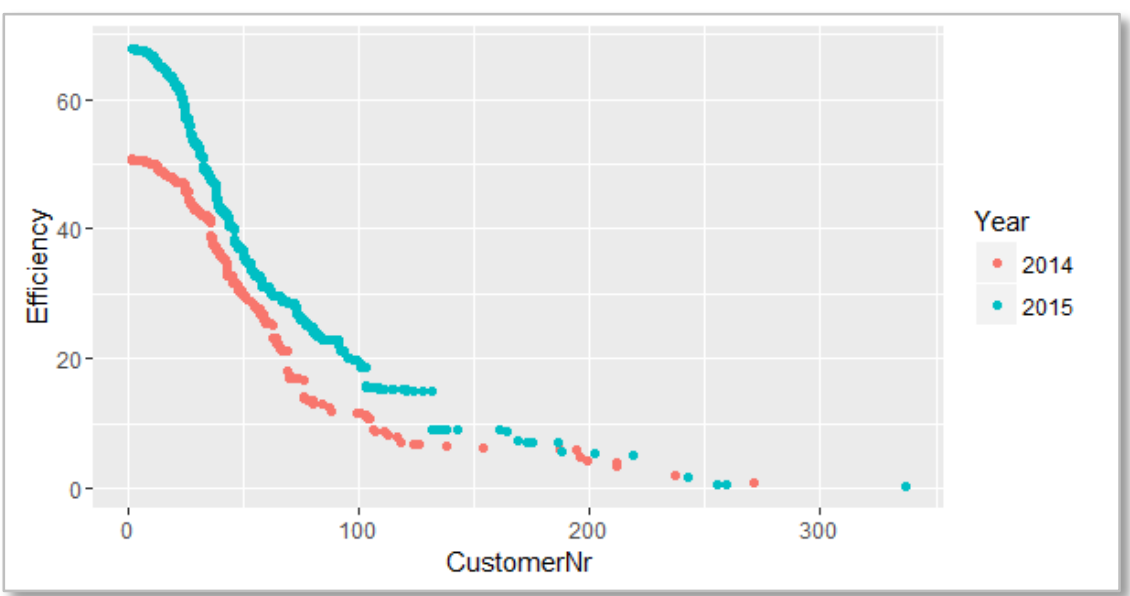

Figure 9

Efficiency in 2014/2015 observations

The data in Figure 9 shows an exponential distribution. The cumulative efficiency function decreases exponentially with the increase of the number of customers $N$, that is with the exponential increase (see Figure 7) of the number of implemented devices.

\subsection{The Determination of the Efficiency Function Using the Regression Analysis}

The curve from Figure 9 regarding the measured data in year 2015 has been determined using regression analysis. The regression model was developed by using the 3rd order polynomial regression according to which:

$C U(N)=74.526-0.8611 \cdot N+0.003317 \cdot N^{2}-0.000004095 \cdot N^{3}$

The function of the estimation fits closely the data measured according to the statistic features: it describes the measured data inasmuch as $96.96 \%$ (see Section $6)$.

The representation of the function (6) and the measured data of 2015 is given in Figure 10. 


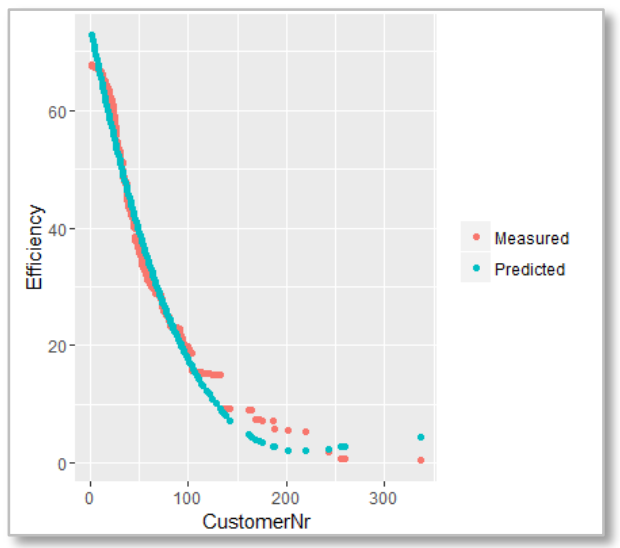

Figure 10

Efficiency and costumer number, $20153^{\text {rd }}$ order regression model

The Figure 10 shows that the data for over 100 customers is under represented (for more details see section 6). However, it illustrates properly the matching between the model and the measured data in the lower ranges.

Hence:

The second recommendation of the research group to the electricity suppliers is to use the efficiency function for determining the number of customers by which it is worthwhile to upgrade the switchboards to SSB's with reclose function. Boundary condition: $N<100$ (for details see section 6).

In Figure 11 the data measured in year 2014 are shown in the same diagramm with the data of the regression model from year 2015. If the regression model would forecast the expected improvement with $100 \%$ certainty, then the value of the green "error" curve should converge to zero everywhere. The green "error" curve represents the difference between the two functions.

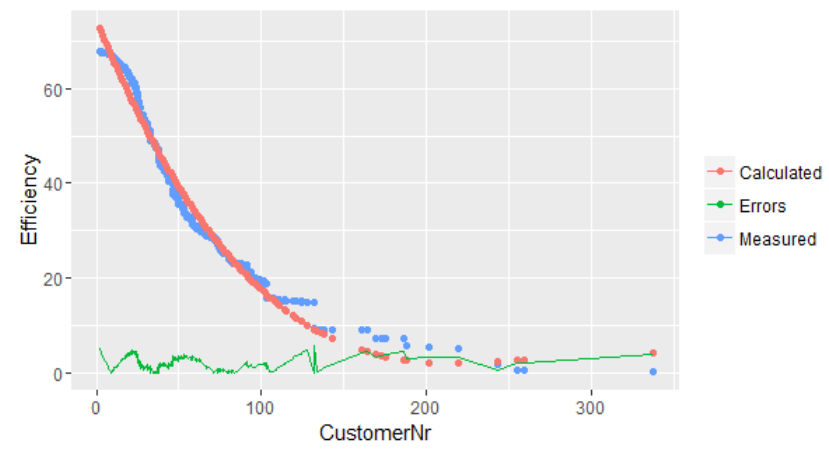

Figure 11

Efficiency and customer number year 2014 using $3^{\text {rd }}$ order regression model of 2015 


\section{The "Platform Anomaly" in the Measured Results}

It can be observed that the shape of the curves for customer numbers between 100 and 180 is levelled. In this interval the efficiency indicator remains almost constant although the number of customers increases. The cause of this so-called "platform" anomaly is discussed in Section 6.

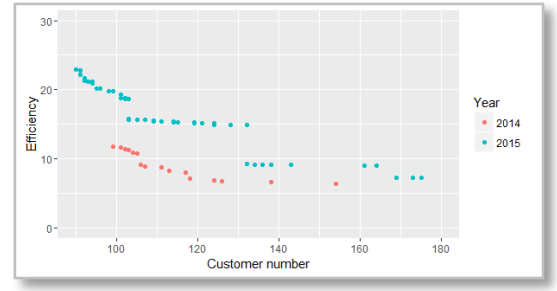

Figure 12

The efficiency curves

in years 2014 and 2015

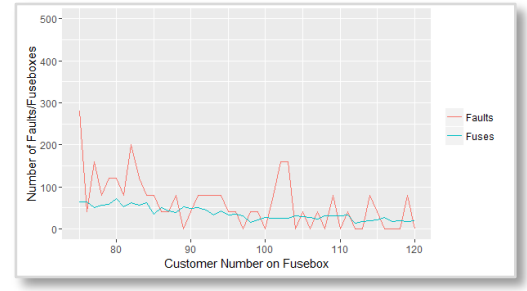

Figure 13

Distributions of the costumers number behind the faults and fuse boxes

\subsection{The Sectioned Efficiency Function}

Due to the anomaly presented in Section 4 the research team cut the efficiency function in 3 different sections. The boundaries of the sections are:

1. $0-102$

2. $103-131$

3. $132-337$
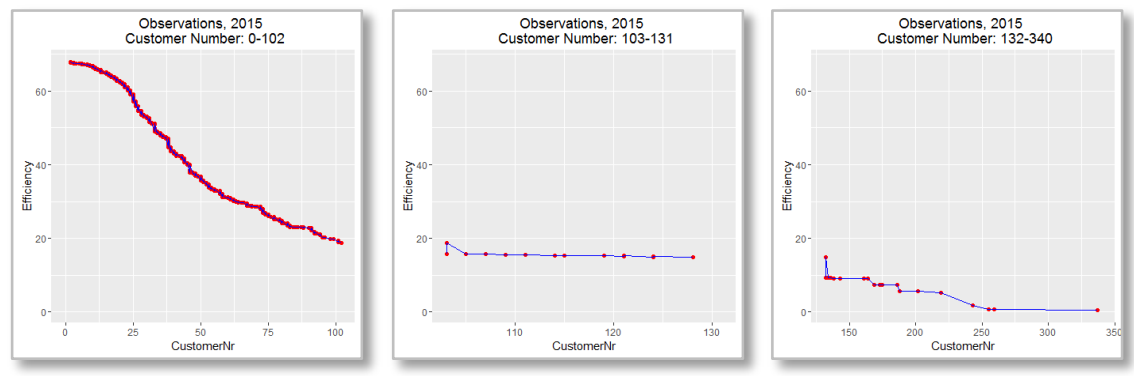

Figure 14

The measured efficiency function in year 2015 divided in three sections

In the first case the polynomial- while in the second case the linear regression model was used. In the third case due to the small number of data (19 pcs observations) the second degree polynomial regression has been applied.

The results obtained by this procedure are the following: 


$$
\begin{aligned}
& C U(N)_{0<N<103}=66.36+0.5309 \cdot N-0.05254 \cdot N^{2}+0.0007689 \cdot N^{3}- \\
& 0.000003444 \cdot N^{4} \\
& C U(N)_{102<N<132}=22.11972+0.5803 \cdot N \\
& C U(N)_{131<N<337}=27.82-0.1573 \cdot N+0.0002191 \cdot N^{2}
\end{aligned}
$$

The three models supperposed in one coordinate system are shown in Figure 15. The representation of the three functions supperposed with the measured data is given in Figure 16.

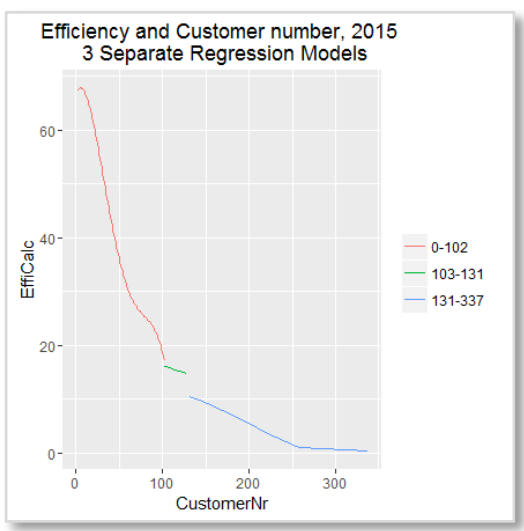

Figure 15

Three efficiency functions from year 2015 supperposed in one diagram

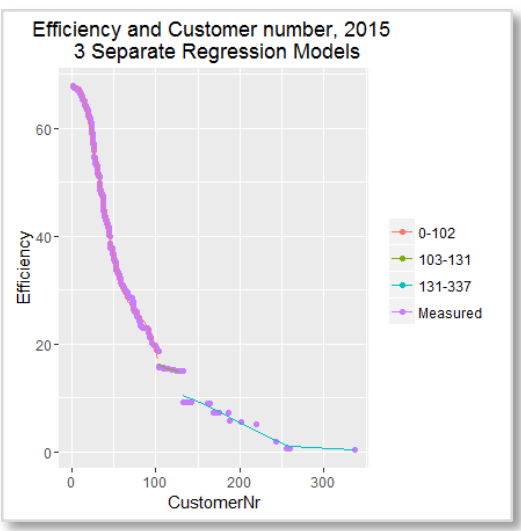

Figure 16

The divided into three efficiency function in 2015 in one figure with the mesured data

In Figure 16 it can be seen that the separated regression models describes more accurately the measured data than the model shown in Figure 11. However, the research group does not recommend to the electricity suppliers the usage of this model due to the reasons described in Section 6.

\section{The Accuracy of the Model}

The statistic model is an estimation based on the statistical data used to create the model itself. Thus, a regression model will give the function which describes a curve closest to the sample points. The function itself is not necessarily passing exactly through the given points.

There are available certain indices which qualify the model:

1. $\mathrm{p}$ value and t-test: these show if there is any correlation between the data and the degree we can relay on it. If $|\mathrm{t}|>2$, then we can state with a 
reliability of $95 \%$ that there exists a correlation. For $|\mathrm{t}|>2.6$ we obtain $99 \%$ reliability.

2. $R^{2}$ : in the present context its value gives the percentage ratio of the description of the sample by the model. In case of the non-separated model its value is $96.96 \%$ which confirms a high level superposition (with the reserves described in section 4.1)

3. Standard Deviation: in the present context it shows how close the actual values are in relation to the expected values. In case of a non-separated efficiency function it is 2.6 at the beginning of the series of data. However, by the end of the series, this number is above 70 .

4. Residuals: the difference between the values calculated with the measured and the model data which stands for the error. See Figure 11.

The above confirms that the models describe properly the measured data.

The compliance of the non-separated regression model is limited by the fact that for over 100 customers $(N)$ only few measured data is available. This fact could significantly change the model. One of the reasons for "platform anomaly" is also due to this fact. Because of this under-representation, further development of the non-separated model is recommended. The disadvantages of this model can be elimininated by more frequent sampling.

\section{Conclusion}

The manual processing of the entire data is limited. The current aim of the AD\&TE research group is to organize and to transform the entire data in order to analyze it with machine learning methods. Using the descriptive data (including the free texts) predict with simpler random forest and more complicated neural network whether a certain event is an error manageable by SSB or not. By this method, the entire data could be examined. This would result in the set up of a more accurate model.

As next step, the research group plans to examine the impact of the weather conditions on the LV power outages' data.

\section{Acknowledgment}

The research was supported by József Fodor, CEO of the ELMÜ Network ltd. and the ELMÜ Network ltd., Tibor Fejes from ELMÜ Network 1td, and Dr. András Köpecsiri, Tímea Kogyela and the leader of the AD\&TE research group: Ferenc Novothny, Ph.D.

\section{References}

[1] Dr. F. Novothny, Power System I, Kandó Kálmán Faculty of Electrical Engineering, Óbuda University, Budapest 2010 
[2] "1366-2012 - IEEE Guide for Electric Power Distribution Reliability Indices" Revision of IEEE Std 1366-2003 (Revision of IEEE Std 13661998), May 31 2012, DOI:10.1109/IEEESTD.2012.6209381

[3] T. Portik, L Pokorádi: The Summarized Weighted Mean of Maxima Defuzzification and Its Application at the End of the Risk Assessment Process, in Acta Polytechnica Hungarica, Vol. 11, Issue 3, 2014, pp. 167180, DOI: 10.12700/APH.11.03.2014.03.11, ISBN: 1785-8860

[4] B. Barze, A. Sharma, A. L. Barabási: Graph Theory Properties of Cellular Networks, Handbook of Systems Biology - Concepts and Insights, Chapter 9, Academic Press, Elsevier, 2013, pp. 177-193, ISBN-13: 97801023859440

[5] H. Li, R. Yeh, Y. Lin, L. Lin, J. Zhao, C. Lin, I. J. Rudas, Medical Sample Classifier Design using Fuzzy Cerebellar Model Neural Networks, Acta Polytechnica Hungarica, Vol. 13, No. 6, pp. 7-24, 2016

[6] J. Pálfi: Localization of Faults in Low Voltage Networks by the Graph Method, in Proceedings of the $11^{\text {th }}$ IEEE International Symposium on Applied Computational Intelligence and Informatics SACI 2016. Conference: Timisoara, Roumania, 2016.05.12-2016.05.14., 2016, pp. 397400, ISBN: 978-1-5090-2379-0

[7] J. Haakana, J. Lassila, T. Kaipia, J. Partanen, Comparison of Reliability Indices From the Perspective of Network Automation Devices, Power Delivery IEEE Transactions, Vol. 25, pp. 1547-1555, 2010, ISSN 08858977

[8] A. Varga, E. Rácz and P. Kádár: New Experimental Method for Measuring Power Characteristics of Photovoltaic Cells at Given Light Irradiation; IEEE $8^{\text {th }}$ International Symposium on Applied Computational Intelligence and Informatics, SACI 2013, Timisoara, Romania, Print ISBN: 978-14673-6397-6, DOI: 10.1109/SACI.2013.6609008, 2013, pp. 405-409, May 2-25, ISBN: 978-146736400-3, Source Type: Conference Proceeding, Original language: English, DOI: 10.1109/SACI.2013.6609008

[9] Zs. Mitrik: Operation of Third Generation Sulphur-Hexafluoride Circuit Breakers in Medium Zone of Short Circuit Currents, Kandó Kálmán Faculty of Electrical Engineering, XXXI. Kandó conference 17. 11 2016, Óbuda University, Kandó Kálmán Faculty of Electrical Engineering, pp. 53-54, ISBN 978-963-7158-07-0

[10] Pausits P, Szögi G, Nallbani M, Rudas I J, Haidegger T: Identification of Risks in the Application of Surgical Robotics, $19^{\text {th }}$ IEEE International Conference on Intelligent Engineering Systems, Bratislava: INES 2015, pp. 147-151, ISBN:978-1-4673-7938-0

[11] K. Zou, W. W. Keerthipala, S. Perera, "Saidi Minimization of a Remote Distribution Feeder" in Australasian Universities Power Engineering 
Conference AUPEC, Perth, Australia, 2007, pp. 342-346, ISBN 9780646494883

[12] J. Kopják, J. Kovács: Timed Cooperative Multitask for Tiny Real-Time Embedded Systems, Applied Machine Intelligence and Informatics (SAMI) 2012 IEEE $10^{\text {th }}$ International Symposium on, 2012, pp. 377-382, DOI: $10.1109 /$ SACI.2011.5873022

[13] R. E. Precup, S. Preitl: Stability and Sensitivity Analysis of Fuzzy Control Systems. Mechatronics Applications, Acta Polytechnica Hungarica, Vol. 3, No. 1, pp. 61-76, 2006

[14] R. E. Precup, C. A. Dragos, S. Preitl, M. B. Radac, E. M. Petriu: Novel Tensor Product Models for Automatic Transmission System Control, IEEE Systems Journal, Vol. 6, No. 3, pp. 488-498, 2012

[15] I. J. Rudas, J. Gáti, A. Szakál, K. Némethy: From the Smart Hands to TeleOperations, Acta Polytechnica Hungarica Vol. 13, No. 1, 2016, pp. 43-60, DOI: 10,12700 / APH.13.1.2016.1.5

[16] Impact of TCSC on the Transient Stability / Zsolt Čonka, Michal Kolcun 2013. In: Acta Electrotechnica et Informatica. Roč. 13, č. 2 (2013), s. 5054. - ISSN 1335-8243

[17] A. L. Kazakov, A. Lempert: On Mathematical Models for Optimization Problem of Logistics Infrastructure, International Journal of Artificial Intelligence, Vol. 13, No. 1, pp. 200-210, 2015 